\title{
A Study on the System of Military Chess Promotion for Refugees in Urban Waterlogging Disaster
}

\author{
Jianhua Bao, Peng Chen, Shuo Zhang, Hongyang Zhao
}

College of Tourism and Geographical Science,Jilin Normal University,Siping 136000,China

\section{城市内涝灾害居民避难兵棋推演体系研究}

鲍建华, 陈鹏, 张硕, 赵洪阳

吉林师范大学旅游与地理科学学院, 吉林 四平, 136000, 中国

\begin{abstract}
Urban waterlogging disaster poses a great threat to the safety of residents' life and property, so the study on the residents' safety of urban waterlogging disaster has been paid more and more attention.Taking the daoli district of Harbin as the research object, the application of military strategy is used to study the emergency refutation system for residents with water logging disaster. The deduction system is carried out from the three elements of the game and the model of the game, the design has both the characteristics of the conventional military design and its own characteristics. In the simulation space of historical disaster, it is necessary to set up the countermeasure and parameter property and the rules of the game according to the principle of chess design. Using the decision tree method to design the game model for the evacuation of residents' waterlogging disaster. The results can provide the basis for the emergency management of urban waterlogging disaster.
\end{abstract}

Keywords: Urbanwater logging, Residents asylum, War game exercise

\section{摘要}

城市内涝灾害对居民生命财产安全构 成极大威胁, 因此对城市内涝灾害居民避难 的研究得到广泛重视。以哈尔滨市道里区为 研究对象, 应用兵棋推演方法, 对内涝灾害 居民应急避难推演体系进行研究。推演体系 从兵棋三要素和兵棋推演模型开展, 设计既 具有常规兵棋设计特点, 也具备自身特色。 实现了在历史灾害仿真空间下，依据棋子设 计原则设定符合居民内涝灾害避难特点的 对抗棋子及参数属性、兵棋规则。运用决策 树方法按居民内涝灾害避难过程设计了兵 棋推演模型。研究结果可为城市内涝灾害应 急管理提供决策依据。

关键词: 城市内涝; 居民避难; 兵棋推演

近年来, 多数大城市都深受城市内涝灾 害影响, 对居民生命财产及社会交通构成极 大威胁 [1-2]。兵棋技术起源于德国, 在后 续发展过程中, 美、英等国家对兵棋推演体 系模型、兵棋推演核心内容棋子及规则的提 取和构建上展开研究 [3]。兵棋推演实质是

“纸上谈兵式” 的决策后态势推演, 通过推 动棋盘上的对战棋子与危机事件相搏弯的 手段来历练棋子对战本领, 同时使得对弯结 果可视化、最适化 [4]。美国针对多种灾害 类型仿真与应急演练开发了 ADMS 灾害管理 模拟系统, 台湾参考美国灾害管理模拟经验, 建立了适宜自身情形的灾害兵棋推演系统 
[5]。在兵棋技术、GIS 技术和现代计算机技 术的支持下, 承敏钢 [6], 陈鹏 [7]等学者应 用兵棋技术对城市灾害应急管理方面展开 研究，构建了适合城市灾害应急管理的兵棋 推演模型和评价方法。学者们的研究内容是 在兵棋地图上仿真灾害事件发生的时间和 地理空间，以对战棋子模拟城市灾害危机状 态及处置力量, 用骰子模拟事件中的不确定 因素, 完成推演灾害事件发生过程。在具体 模拟过程中, 需设定灾害发生背景, 作战目 标及对战回合时间, 推演棋子从初始位置展 开行动, 各推演方通过走棋的方式用灾害情 况之间展开对抗, 设定者对连续产生的灾害 危机态势进行阶段性裁决。进行灾害应急管 理目的是在投入低成本情况下，仿真实际危 机情况, 展开应急演练, 发现政府决策漏洞, 提高城市灾害危机应急管理水平。目前, 学 者对城市灾害应急管理的研究多是从政府 层面予以设计研究, 政府应急管理部门尚存 在部门分割, 管理主体单一, 信息机制及社 会合作机制未形成等问题, 政府在城市危机 应急管理方面尚存在反应不时, 决策不智, 处置不适的情况 [8]。

因此, 本文从 “自助, 共助, 公助” 三 角度着手, 以避难居民为核心, 进行城市内 涝居民应急避难推演体系研究, 以改善现在 城市灾害危机应急管理中存在的不足, 为居 民避难兵棋推演研究提供参考。研究目的是 全面准确地把握居民避难过程信息, 精准地 改善居民避难时的薄弱环节和不足之处, 帮 助政府挑选避难过程中的薄弱人群, 帮扶客 观居民及时摆脱危险情况。

\section{1 内涝灾害居民避难兵棋推演理论}

基于兵棋推演的城市灾害应急管理系 统是利用现代计算机技术进行编程, 用计算 机软件的形式将城市灾害历史情景数据信 息化。本文对于实际灾害问题进行仿真模拟、 推演计算、构建相应的模型及规则, 模拟在 未来灾害条件变化情况下的虚拟综合环境, 用以预测未来灾害变化情况。学者们利用危 机与处理之间的博亦关系，模拟政府救援情 况, 检验政府救援决策方法, 训练政府指挥 能力 [9]。在内涝灾害事件发生过程中, 由 于政府与居民避难背景信息, 行动方式, 达
成目的一致, 为完善政府对内涝灾害的应急 管理, 故将兵棋推演方法应用到城市内涝灾 害居民应急避难研究中。

内涝灾害居民避难兵棋推演基本理论 是用代表灾害环境和内涝的棋子和棋盘, 依 据居民在内涝避难中总结的规则, 对居民避 难过程进行推演和评估, 对居民避难过程进 行预测、模拟、观察。设计过程是在想定灾 害背景信息下, 从居民角度开展, 用推演棋 盘来仿真模拟城市内涝危机空间, 采取时间 回合制, 动态模拟城市危机变化情况。其中, 用棋子模拟城市危机中的处置力量因素, 用 兵棋规则模拟居民避难规律, 用随机数（骰 子）模拟城市危机状态及处置的不确定性和 复杂性, 回合式的模拟体现出棋子对危机态 势裁决处置的过程。

居民在城市内涝避难过程中，更倾向于 先自救, 而后共助互救, 最后依赖政府救援, 但在过程中政府救援是最直接、最有效的方 式。政府在灾害发生前的预警发布、灾中的 紧急救援、灾后的救援安置, 都对居民避难 素质及状态产生直接影响, 居民在避难行为 选择中也依赖政府给予的引导。居民避难过 程推演研究依托政府救援过程为事件发生 主线, 居民发生自主避难过程, 体系设计分 为准备、危险撤离、政府救援、安置救援四 个阶段。研究运用博弯论、统计学等科学方 法, 对各类灾害数值和人员行为进行模拟, 使避难居民依据自身情况, 物资信息选择行 动方案和了解情况信息, 明确居民在遇危机 环境时可发生的行为选择。推动居民棋子依 据回合制移动速度, 在空间格网地图上发生 移动, 从危机状态至稳定状态, 过程中, 居 民棋子自身属性值同内涝灾害棋子属性值 进行阶段性裁决。推演过程终止时, 根据属 性值的改变, 判断居民状态及安全, 了解不 同属性战损情况、程度及后续影响。研究需 要在 GIS 技术支持下对行政区划等地理数据、 降雨气象数据; 排水管道, 紧急避难所等城 市设施数据; 居民点分布数据; 居民应急素 质和内涝避难行为选择调查数据; 政府救援 相关力量等数据进行有效整理、处理、分析、 应用。针对上述内容设计如下流程图 (图 1)。 


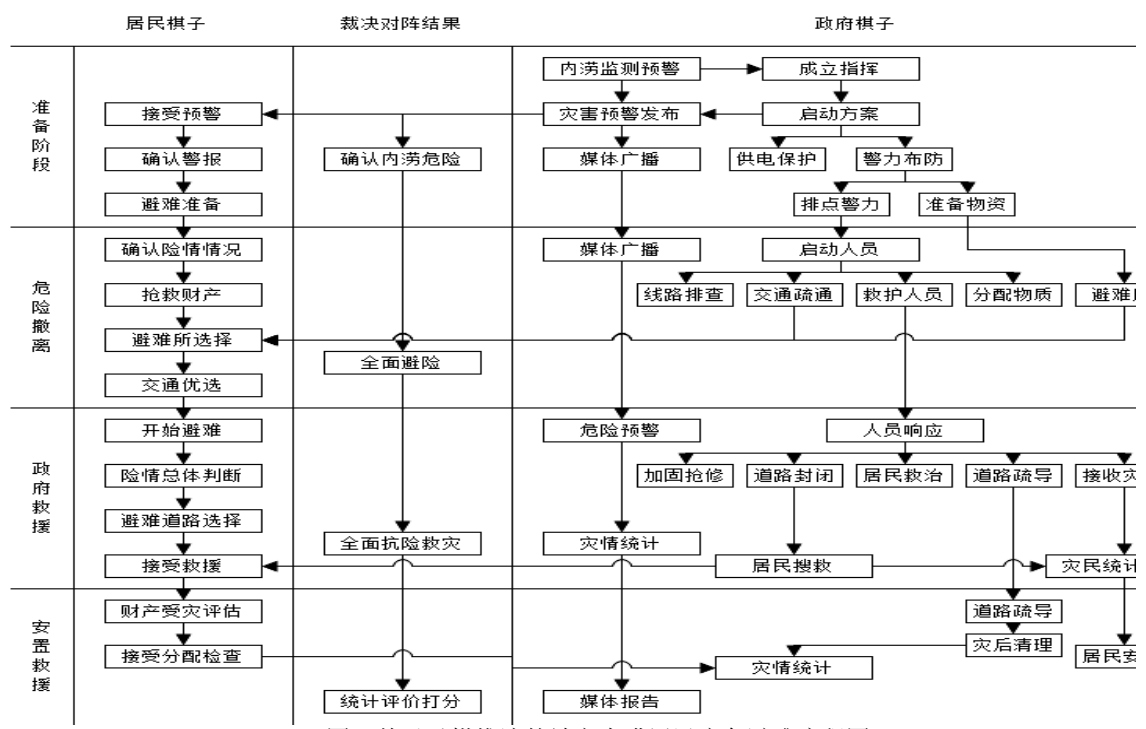

图 1 基于兵棋推演的城市内涝居民应急避难流程图

\section{2 兵棋推演要素设计}

\section{1 地图绘制}

对比正方形网格与正六边形网格, 发现 后者对角线误差值最小, 为 $2 / 3 \approx 1.15$, 所 以本文采用六角形网格 [10]。下两图分别为 正方形网格与正六边形网格对比图 (图 2) 和误差对比图 (图 3)。
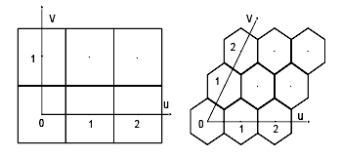

图 2 正方形网格与正六边形网格对比
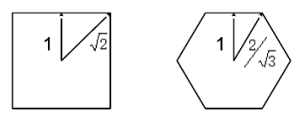

图 3 正方形网格与正六边形网格误差对比

以哈尔滨市道里区为例, 本文统计分析 研究区环境数据资料包括哈尔滨市快鸟影 像、DEM、1: 1 万地形图、城市排水管网分 区数据、道里区降水数据、历史积涝数值、 居民地等信息。将历史降雨数据资料通过系 统调用传入城市暴雨积涝危险性数值模型 中, 通过模型计算出道路积水水深, 流速等 相关数据 [12]。本系统中的兵棋地图采用
Patch Grid Plugin 插件, 引入 到 ARCGIS10. 2 软件中, 直接绘制正六边兵棋 网格地图, 利用 ARCGIS 软件的属性关联, 将下垫面信息关联到兵棋地图中, 最终生成 研究需要的矢量兵棋地图。

\section{2 棋子设定}

兵棋棋子是对参与作战单位的抽象总 结及概括, 并标有单位棋子的作战能力及特 点信息。其标注属性信息的意义是指, 通过 所总结的实际单位行动规则同敌对方展开 激烈的对弯, 最后将结果通过棋子相应作战 能力参数属性的数学逻辑运算在维度上予 以表现 [11]。内涝爆发时间迅速, 水位上升 迅猛, 冲击力弱, 水位到达峰值时, 对居民 财产威胁最大, 居民生命安全较弱, 随后水 势减弱。兵棋棋子设定时遵循通用棋子设定 方法, 为突出居民内涝避难兵棋的领域特色, 展开居民和政府棋子同内涝灾害棋子对抗, 并对居民财产进行衡量。居民内涝避难棋子 的设计过程是在具体的灾害发生背景中, 根 据居民对抗内涝的实际作战情况, 提取出能 够有效衡量参与对抗内涝灾害的棋子参数 属性, 并在一个等价的赋值体系中运用数学 模型对提取到的参数属性进行数值量化。棋 子设计遵循一定设计原则, 包括准确反映参 
与对抗内涝的作战实体的性能特点、属性特 征和参战地点, 有效的融入联合或合同交战 理念, 有效的度量参与对抗的属性, 正确体 现居民避难对抗内涝的作战特点。

\section{(1) 居民棋子}

居民是避难救援的保护中心和行为控 制中心, 设计棋子参数属性时 (表 1), 重点 提取影响居民抗灾能力的身体情况和影响 居民避难实施的交通设备, 以及影响居民避 难行为选择的财富状况, 准确反映居民在辅 助推演者进行战场决策中的地位及作用。居 民初始态势的不同会导致不同心理状态, 将 会对居民属性产生一定影响, 改变居民行为 选择情况。依据财富状况和遇险分布人数状 态分为: 个人独立棋子 (1 人) 包括个人个 体，个人居民两类; 家庭棋子（2-3 人）包 括家庭个体、个人居民; 群体棋子 (4-人)。 从居民棋子的防御力, 攻击力两方面着手, 对居民自保, 保物, 救人三方面提取属性进 行赋值。

表 1 居民棋子属性表

\begin{tabular}{|c|c|c|}
\hline $\begin{array}{l}\text { 影响居 } \\
\text { 民避难 }\end{array}$ & \multicolumn{2}{|c|}{ 属性 } \\
\hline 个人 & 个人防灾素质 & $\begin{array}{c}\text { 个人活动能 } \\
\text { 力 }\end{array}$ \\
\hline 外在 & 车辆抗灾值 & 车辆载人值 \\
\hline 财富 & 财产活动值 & $\begin{array}{c}\text { 移动困难程 } \\
\text { 度 }\end{array}$ \\
\hline 应急而生 & 应急心理能力 & 抗灾理智度 \\
\hline
\end{tabular}

（2）政府棋子

根据《中华人民共和国防汛条例》和《中 国人民共和国突发事件应对法》规定, 灾害 发生时在政府的领导下各政府机构协同合 作抗险, 确定政府在城市内涝避难相关机构, 设立政府棋子。政府棋子的作用效果等同于 保障棋子, 在战争中提供后勤补给物资, 帮 助居民棋子取得避难成功。设计政府棋子时, 选取于过程中对居民行为产生影响的单位, 并对其影响效果做度量。政府棋子包含情报 侦察预报棋子, 后勤保障安置棋子, 技术指 挥作战棋子, 有利打击对方棋子, 医疗救助 棋子(图 4)。下表为政府棋子增加居民棋子 赋值方面表 (表 2)。

(3) 内涝棋子

内涝棋子的作战对象是居民棋子和政 府棋子, 其目的是随着空间、时间以及环境 情况的变化对敌对方原来的部署计划做出 干扰和破坏, 其打击效果是通过棋子属性的 折损值来表现。内涝棋子的变化过程是积水 不断加深, 位置不发生移动, 范围进行扩大。 避难过程中, 未排除的洼地积水阻断交通、 阻碍居民出行、威胁居民生命安全。内涝棋 子属性值在过程中随时间、环境的发展而不 断发生变化, 因此对居民棋子属性值的打击 也在不断发生改变。两方棋子相遇时, 属性 值发生折损, 当某一方面属性值达到结点态 势以下, 判定所带此属性值的棋子状态发生 变化或安全构成威胁。

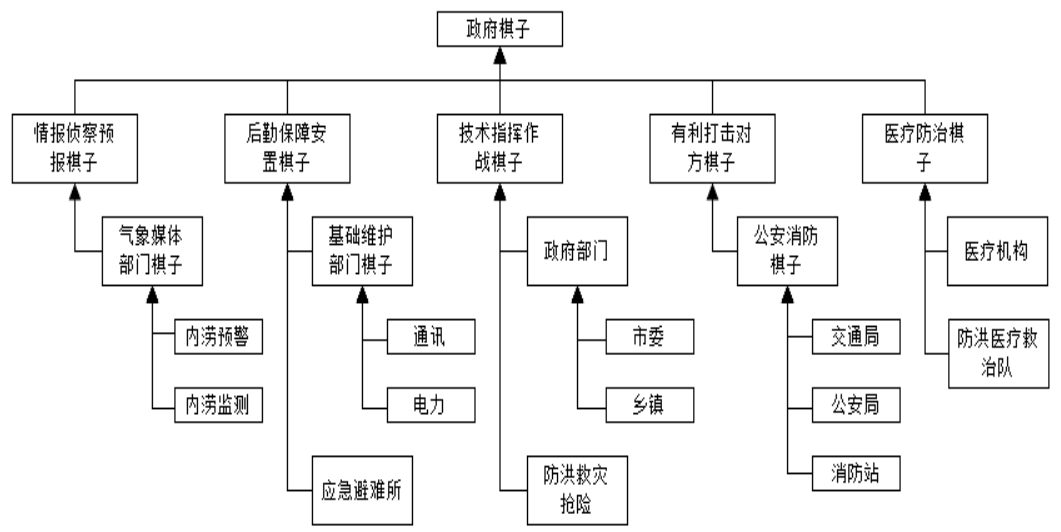

图 4 政府棋子 
表 2 政府棋子对应居民棋子属性表

\begin{tabular}{ccc}
\hline 推演 & 推演具体部门 & 增加居民棋子方向 \\
席位 & & \\
\hline 气象 & 气象局、市宣传 & 个人防灾素质、应急 \\
媒体 & 委 & 心理能力、抗灾理智 \\
部门 & & 度 \\
基础 & 市供电局、市水 & \\
维修 & 利局、市经信委 & \\
部门 & & \\
安全 & 市民政局、安置 & 个人活动能力、应急 \\
避难 & 管理中心 & 心理能力、抗灾理智 \\
所 & & \\
政府 & 应急中心, 裁决 & \\
机关 & 组 & \\
部门 & & \\
公安 & 武警支队, 公安 & 车辆抗灾值, 车辆载 \\
消防 & 局, 市交通局, & 人值, 移动困难程 \\
部门 & 市排水公司, & 度, 应急心理能力, \\
& & 抗灾理智度 \\
医疗 & 市卫生局 & 个人活动能力, 车辆 \\
救助 & & 载人值 \\
部门 & & \\
\hline & 从内涝棋子的积水深度, 积水面积, 水
\end{tabular}

从内涝棋子的积水深度, 积水面积, 水 流速度三方面进行属性赋值 [12]。计算内涝 棋子的方法是根据哈尔滨市道里区回合降 雨量表, 计算降雨损失, 其中包括初损、截 留和洼蓄、入渗损失及排水管网的排水量损 失。其计算公式为: 六格网积水量计算公式: $V=P D-J-R-q \max (1)$ 式中, $\mathrm{v}$ 为六 角网格积水量; $P D$ 为降雨强度; $J$ 为截留损 失; $R$ 为水力半径; $q \max$ 为流量。

积水深度的计算公式为: $h=V / S$ (2) 式中, $h$ 为六角网格积水深度; $V$ 为六角网 格积水量, 即: $V=P D-J-R-q$ max $; S$ 为六角 网格积水面积。最后算得道路积水流量与深 度。

\section{3 规则设定}

规则设定是兵棋设计的核心内容, 它是 使兵棋推演过程规范、裁决交战结果有依据 的基础。规则制定依据来源于对真实历史事 件和演习训练救灾经验规律的深刻总结。规 则设定的目的是将真实的作战交锋的过程, 通过兵棋规则对棋子的参数属性, 在裁决过
程中进行限制与简单逻辑运算。按兵棋规则 的分类, 居民避难兵棋规则设计的具体内容 包括棋子实体规则、行动规则、移动规则和 裁决规则。

棋子实体规则是对避难实体进行环境 实力特征定量化描述的约束条件, 主要包括 避难实体类型, 属性特征, 拥有物资器材及 损耗规则等, 如一: 成年男子, 当水深 1. 0-0. $3 \mathrm{~m}$, 流速 $0.1-0.5 \mathrm{~m} / \mathrm{s}$ 时, 可以步行; 水深 0.5-1. $0 \mathrm{~m}$, 流速 0.5-1.0m/s 时, 出行 困难有危险; 水深 $1.0 \mathrm{~m}$, 流速 $1.5 \mathrm{~m} / \mathrm{s}$ 以上 时, 不可出行; 有小船等同类交通工具不考 虑水深皆可以出行。保障实体类型主要是指 保障部队人员力量、保障物资、抢救器材、 抢险车辆等, 如: 在避难过程中遇到政府医 疗救治团队, 居民安全得到保障并拥有避难 交通工具。棋子行动规则是指对避难过程中 各种活动行为进行约束性的描述, 列出必备 的行为条件, 约束条件和影响行动的环境条 件等, 如: 居民在自身家庭避难选择过程中, 没有沙袋, 玻璃, 木板, 勺子或水桶等排水 物资时, 不可进行自主排水等自身行为条件 限制规则。棋子移动规则是以实体行动速度 与到达目的地的距离, 按回合计算在六格网 地图移动时间。棋子裁决规则是指在灾害避 难过程中必然出现的规律的规则, 反映的是 行动效果及结果, 如: 接受到电视媒体, 亲 人邻居, 工作区域预警, 亲身见到道路积水 情形, 道路预警等明确灾害现象的事件显示 居民接收预警, 会进行正常避难过程等事件 发生判断。

\section{3 兵棋推演模型}

\section{1 模型构建方法}

决策树算法是以实例为基础进行归纳, 因其理论清晰易于被人们理解, 算法复杂度 小, 较高的分类准确率, 易显示规则等优点 而得到广泛应用 [13]。决策树的本质是以一 种类似流程图形势来表示决策问题, 通过建 模为决策序列, 随机事件和结果, 并将它们 按一定顺序排列。决策树由根节点、分支、 叶结点所构成, 结点相连接的不同分支对应 这个属性的不同取值, 根据不同的属性相继 转入不同分支, 如此判断直至这一过程达到 
某个叶结点。

本文采用决策树算法按居民应对灾害 事件行为顺序, 以方框表示一个决策节点, 用圆圈表示每个分支一个叶结点, 一条线段 链接决策节点与叶结点表示一种类别事件 行动过程, 代表居民的一种选择和事件情况, 每条线段上标注的数字表示每种事件发生 的概率。各分支结点都有一个结果值, 该值 表示初始态势属性值沿决策树模型路径的 决策集和其中的随机事件属性影响后的结 果值。利用决策树思想, 分解居民同内涝灾 害对抗避难过程, 在决策树上有序分配。

\section{2 推演模型构建}

推演模型构建需仿真居民进行城市内 涝避难的过程, 模拟出居民在灾害发生过程 中面临的突发事件, 限制因素和行为选择的 顺序过程。依据调查研究, 显示影响居民内 涝灾害避难的两大重要方面, 一是居民生命 安全、二是财富安全。在保障居民安全的前
提下, 居民进行财产救援环节是在整个灾害 避难过程中, 最重要影响避难时间的环节之 一。将内涝灾害爆发环境特点结合居民自我 判断避险相结合, 建立针对居民城市内涝避 难行为的推演路线 (图 5), 并将其划分为准 备避难、危险撤离阶段、政府救援、安置居 民四个阶段。

对居民避难过程遇到选择情况进行统 计分析, 以决策树算法对数据进行挖掘和归 纳, 建模决策树列。将居民预警接受作为决 策树根节点, 明确具体分类情况设置判别条 件, 设置不同分支情况值, 到达分支节点时 重复选择。居民棋子初始携带属性值, 按一 种类型居民不同分支选择概率进行分支分 类选择, 同时居民棋子属性值发生增减, 遇 特殊自然情况或偶然的社会情况, 依据补充 数值规则设定对属性增减, 直至居民棋子处 于稳定态势时终止自主避难过程。下图为部 分居民内涝避难决策图 (图 6)。

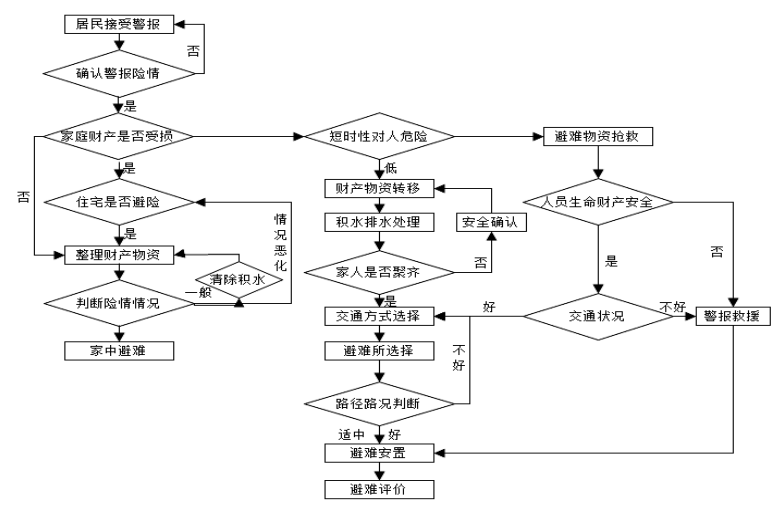

图 5 居民城市内涝避难行为的推演路线

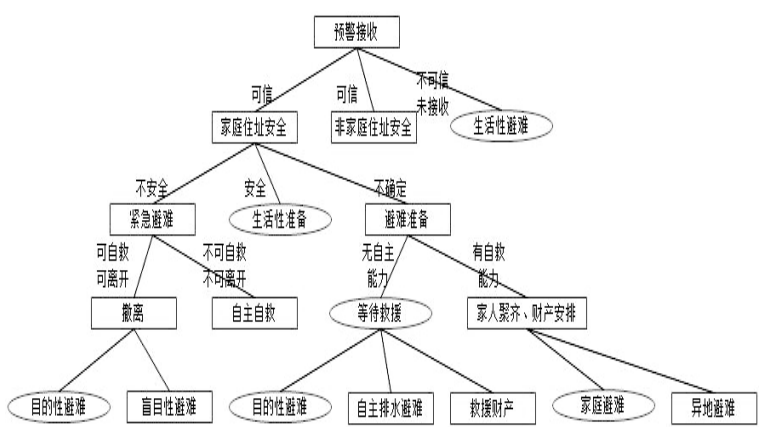

图 6 部分居民内涝避难决策图 


\section{4 结论与讨论}

随着现代计算机技术的发展和兵棋理 念的推广, 应用兵棋技术对城市灾害发生情 景进行仿真模拟得到广泛关注, 将兵棋推演 的方法引入城市内涝居民避难过程, 为兵棋 推演在危机救援方面提供新的思路。本文应 用兵棋推演原理对城市内涝灾害居民避难 体系进行设计, 具有较强针对性, 区别政府 灾害救援管理推演, 从居民角度进行兵棋推 演三要素和推演模型设计。将居民对抗内涝 灾害相关作战行动融入兵棋推演中, 强调对 避难历史经验的重视, 突出实际灾害事件背 景, 构建基于决策树方法的城市内涝灾害居 民避难兵棋推演模型, 旨在实现居民与政府 机构协同合作。对内涝灾害成功博弯, 有助 于形成政府对居民行为在避难过程中的正 确认识。由于影响居民避难行为产生的因素 复杂多样, 推演展开还需要在居民避难心理 方面进行深入研究。

进行居民内涝灾害避难方面研究, 可以 帮助政府救援工作具体的实施, 而系统可以 动态掌握居民在避难过程中的安全及薄弱 环节, 帮助政府针对性救援群众, 避免救援 资源的浪费, 提高救援时间, 及时准确保证 居民生命、财产安全。本文仅是对居民内涝 灾害兵棋推演的棋子、规则和推演过程的初 步总体性研究, 更多具体性推演细节还有待 后续深入。

\section{致谢}

本研究得到了国家社会科学基金项目 (41501557) 的资助。

\section{参考文献}

[1] 张冬冬, 严登华, 王义成, 等.城市内涝灾 害风险评估及综合应对研究进展. 灾害 学, 2014, 29(01):144-149.

[2] Bevaola K, Quamrul A. Resource capability for local government in managing disaster. Disaster Prevention and Management, 2010, 19(4):438-451.

[3] 彭春光,鞠儒生,杨建池, 等.现代兵棋推 演技术分析.系统仿真学报, 2009, 21(S2): 97-100.
[4] 叶利民,龚立,刘忠.兵棋推演系统设计与 建模研究.计算机与数字工程, 2011,39 (12):58-61.

[5] 柳玉,文家炎,陈建华.计算机兵棋系统发 展及应用研究.兵工自动化, 2015, 34 (08): 20-26.

[6] 承敏钢,江冰,李丽芳.基于兵棋推演理论 的城市危机应急管理体系设计.中国环 境管理, 2014, 6(03):38-42.

[7] 陈鹏,张继权,孙漟悦, 等.城市内涝灾害 居民应急避难兵棋推演理论与方法. 人 民长江,2016,47(14):7-11.

[8] 蔡纪伟,王桂起.装备保障计算机兵棋推 演规则体系.火力与指挥控制, 2013, 38(11):28-31.

[9] Hämäläinen J, Sormunen J, Rantapelkonen, J, Nikkarila J -P. Wargame as a combined method of qualitative and quantitative studies. Journal of Military Studies, 2014, 5(1).

[10] 汤奋,武志强,张欣,等.基于模板的六角 格兵棋地图可视化设计研究. 测绘工 程,2016,25(04):55-59.

[11] 陈鹏,张继权,严登华,等.基于 GIS 技术 的城市暴雨积涝数值模拟与可视化一 以哈尔滨市道里区为例. 灾害学, 2011, 26(03):69-72.

[12] Chen P, Zhang J Q, Sun Y Y, Liu X J. Wargame mapping and implementation for emergency evacuation of residents in urban waterlogging disaster. Journal of Risk Analysis and Crisis Response, 2018, 8(1): 43-51.

[13] U.S. Department of Homeland Security, Homeland Security Exercise and Evaluation Program ( HSEEP). 2013. 